\title{
PENGARUH MEDIA POSTER DAN LEAFLET TERHADAP TINGKAT PENGETAHUAN DAN SIKAP KONSUMSI MAKANAN JAJANAN ANAK SEKOLAH SMP 1 PATAMPANUA PINRANG
}

\section{the Influence of Poster Media and Leaflets to the Level of Knowledge and Attitude in Snack Consumption student sof SMPN Patampanua Pinrang}

\author{
Rismayanti Latif ${ }^{1,}$ Haniarti $^{2}$, Herlina Muin ${ }^{3}$ \\ Fakultas Ilmu Kesehatan Universitas Muhammadiyah Parepare \\ (rismayantilatif@gmail.com)
}

\begin{abstract}
ABSTRAK
Salah satu faktor yang mempengaruhi status gizi anak adalah kebiasaan makan. Kebiasaan anak jajan dapat berdampak buruk sebab banyak makanan jajanan yang tidak aman dan tidak sehat. Beredarnya makanan jajanan yang tidak aman dan tidak sehat dapat berdampak pada anak-anak yang dapat menyebabkan terkena penyakit dan dapat menurunkan status gizi anak. Tujuan penelitian ini adalah untuk mengetahui pengaruh tingkat pengetahuan dan sikap pelajar di SMP sebelum dan sesudah pemajangan poster dan leaflet di Kecamatan Patampanua Kabupaten Pinrang. Tekhnik pengambilan sampel yaitu total total sampling. Pengumpulan data menggunakan kuesioner yang diberikan kepada responden sebelum dan sesudah pemberian poster dan leaflet . berdasarkan analisis dengan menggunakan paired sample T-test diperoleh dengan nilai $=0,000$, ini berarti ada pergaruh tingkat pengetahuan pelajar antara sebelum dan sesudah pemajangan poster dan leaflet, ada pengaruh sikap pelajar antara sebelum dan sesudah pemajangan poster dan leaflet di SMP 1 Patampanua Kabupaten Pinrang
\end{abstract}

Kata kunci : Tingkat Pengetahuan, Sikap, Poster, Leaflet dan Status Gizi

\begin{abstract}
One factor that influences children's nutritional status is eating habit. The habit of snacking has bad impact because many snacks are unsafe and unhealthy. The circulation of unsafe and unhealthy snacks has bad affect to children whichcause illness and can reduce children's nutritional status. The purpose of this research is to know the effect of the level of knowledge and attitudes students of SMPN 1 Patampanua, Pinrang before and after the display of posters and leaflets. This research used total sampling technique. Data collection used questionnaire given to respondents before and after displaying posters and leaflets. based on the analysis using paired sample T-test obtained a value $=0,000$, it means that there is a difference in the level of student knowledge before and after displaying posters and leaflets, there is an influence of students' attitudes before and after displaying of posters and leaflets at SMPN 1 Patampanua, Pinrang.
\end{abstract}

Keywords: Level of Knowledge, Attitudes, Posters, Leaflets and Nutritional Status. 


\section{PENDAHULUAN}

Ketersediaan serta keamanan pangan adalah hak dasar manusia, hal tersebut tercantum dalam Undang-undang No.36 tahun 2009. Setiap hal dapat menyebabkan gangguan kesehatan, termasuk ketidakamanan pangan pada masyarakat Indonesia akan menimbulkan kerugian ekonomi yang besar baik negara, dan setiap upaya peningkatan derajat kesehatan masyarakat juga merupakan investasi bagi pembangunan negara. ${ }^{1}$

Makanan jajanan anak sekolah mempunyai peran penting dalam memberikan asupan energi dan gizi bagi peserta didik/siswa sekolah. Namun, keamanan makanan jajanan anak sekolah masih perlu menjadi perhatian kita semua, masih sekitar 40-44\% makanan jajanan anak sekolah tidak memenuhi syarat. ${ }^{2}$

Data statistik tahun 2002 menunujukkan bahwa wanita yang bekerja pada angkatan kerja berjumlah 33,06 juta atau $44,23 \%$ dari jumlah total usia wanita. Wanita sebagai ibu rumah tangga dan sebagian lain berprofesi bekerja diluar rumah, karena keterbatasan waktu dan kesibukan sehngga banyak ibu rumah tangga yang tidak mempunyai waktu untuk menyediakan menu bagi keluarga. Berdasarkan data yang diperoleh dari BPOM Provinsi Sulawesi Selatan, pada pengawasan pangan jajanan anak sekolah dasar di 16 Kabupaten/Kota menunjukkan $79,8 \%$ sampel memenuhi syarat dan $20,2 \%$ sampel tidak memenuhi syarat. ${ }^{3}$

Salah satu usaha untuk dapat mengurangi paparan anak sekolah terhadap pangan jajanan yang tidak sehat dan tidak aman adalah dengan promosi keamanan pangan.${ }^{4}$ Media cetak sering digunakan karena lebih efektif untuk menyampaikan informasi dan pendidikan gizi, karena mengutamakan pesan-pesan visual, dan umumnya terdiri dari gambaran sejumlah kata, gambar atau foto dalam tata warna yaitu berupa poster, leaflet, brosur, majalah, modul, dan buku saku. Dari beberapa media cetak tersebut yang dapat digunakan dalam penelitian ini untuk anak sekolah diantaranya adalah poster dan leaflet. Adapun tujuan penelitian ini adalah untuk mengetahui Pengaruh Media Poster Dan Leaflet Terhadap Tingkat Pengetahuan Dan Sikap Konsumsi Makanan Jajanan Anak Sekolah Di SMP 1 Patampanua Pinrang.

\section{BAHAN DAN METODE}

Jenis penelitian yang digunakan adalah eksperimen kuasi (quasi experiment) yang dimaksud adalah eksperimen yang memiliki perlakuan, pengukuran dampak. dengan rancangan desain one group pretest-postest. Penelitian ini bertempat di Kecamatan Patampanua Kabupaten Pinrang di SMP 1 Patampanua Pinrang penelitian ini dilaksanakan pada bulan Mei-Juni 2018. Populasi merupakan keseluruhan dari responden. Populasi dalam penelitian ini adalah seluruh pelajar kelas VII di SMP yang berjumlah 171 pelajar. Teknik pengambilan sampel dilakukan secara Total Sampling yaitu jumlah sampel sama dengan jumlah populasi sebanyak 171 pelajar. 
Pengumpulan data primer dilakukan dengan mrngukur tingkat pengetahuan dan sikap pelajar dengan menggunakan kuesioner, yang didalamnya berisi tentang jenis kelamin, kelas dan umur dan pengetahuan tentang makanan jajanan sehat.

\section{HASIL}

Hasil penelitian karakteristik responden yang menjadi sampel penelitian, berdasarkan jenis kelamin yang lebih dominan adalah responden perempuan dengan persentase sebanyak $59,1 \%$ dan laki-laki sebanyak 40,9\%. Berdasarkan karakteristik umur, responden yang berumur 11-13 tahun lebih dominan dengan persentase sebanyak $88,3 \%$, dan terendah berumur 14-16 tahun sebanyak $11,7 \%$. Berdasarkan kelas, lebih dominan di kelas $\mathrm{VII}_{1}$ dengan persentase sebanyak $19,9 \%$, dan lebih sedikit di kelas $\mathrm{VII}_{3}$ dengan persentase sebanyak $14,6 \%$. Sedangkan tingkat pengetahuan konsumsi makanan jajanan sebelum pemajangan poster dan leaflet dapat dilihat bahwa $84,2 \%$ pelajar memiliki tingkat pengetahuan yang tinggi, dan untuk sedang sebanyak $15,8 \%$, sedangkan untuk rendah sebanyak $0,00 \%$. Untuk tingkat pengetahuan konsumsi makanan jajajan setelah pemajangan poster dan leaflet dalam kategori tinggi meningkat menjadi $90,6 \%$, dan menurun di kategori sedang menjadi 9,3\% .

Sikap konsumsi makanan jajanan sebelum pemajangan poster dan leaflet adalah $90,1 \%$ pelajar memiliki sikap baik, sedangkan 9,9\% pelajar memiliki sikap kurang. Sedangkan setelah pemajangan poster dan leaflet meningkat menjadi $98,2 \%$ untuk kategori baik, sedangkan dalam kategori kurang menurun manjadi $1,8 \%$.

Pengaruh media poster dan leaflet terhadap tingkat pengetahuan dan sikap konsumsi makanan jajanan anak sekolah., berdasarkan tabel dilihat bahwa responden yang memiliki tingkat pengetahuan tinggi sebelum pemajangan poster dan leaflet sebanyak $84,2 \%$, dan setelah pemajangan poster dan leaflet meningkat menjadi $90,6 \%$. Sedangkan kategori rendah untuk tingkat pengetahuan responden sebelum pemajangan poster dan leaflet sebanyak $15,8 \%$, dan setelah pemajangan poster dan leaflet menurun menjadi 9,3\%. Dan untuk sikap responden sebelum pemajangan poster dan leaflet sebanyak $90, \%$, dan setelah pemajangan poster dan leaflet meningkat menjadi 98,2\%, sedangkan kategori kurang untuk sikap responden sebelum pemajangan poster dan leaflet sebanyak $9,9 \%$, dan setelah pemajangan poster dan leaflet menurun menjadi $1,8 \%$. Hasil analisis menggunakan uji $t$ berpasangan yang diperoleh ada pengaruh media poster dan leaflet terhadap tingkat pengetahuan dan sikap konsumsi makanan jajanan anak sekolah di SMP 1 Patampanua Pinrang dengan nilai valuenya $(\mathrm{p}=0,000)$.

\section{PEMBAHASAN}

Tingkat pengetahuan pelajar sangat berpengaruh terhadap pemilihan makanan jajanan. Pengetahuan siswa dapat diperoleh baik secara internal maupun eksternal. Untuk 
pengetahuan secara internal yaitu pengetahuan yang berasal dari dirinya sendiri berdasarkan pengalaman hidup sedangkan eksternal yaitu pengetahuan yang berasal dari oarng lain sehingga pengetahuan pelajar bertambah. ${ }^{5}$

Data Tabel 6. Menunjukkan bahwa dari 171 responden, 84,2\% responden yang memliki tingkat pengetahuan tinggi sebelum pemajangan poster dan leaflet meningkat setelah pemajangan poster dan leaflet sebanyak 90,6\%. Responden yang memiliki tingkat pengetahuan sedang sebanyak $15,8 \%$ sebelum pemajangan poster dan leaflet dan menurun menjadi 9,3\% persen setelah pemajangan poster dan leaflet. Sedangkan reponden dengan pengetahuan rendah sebelum pemajangan poster dan leaflet dan setelah pemajangan poster dan leaflet tidak terdapat pelajar yang memiliki pengetahuan yang rendah.

Berdasarkan analisis dengan menggunakan paired sample T-test diperoleh dengan nilai $=0,000$, ini berarti bahwa ada perbedaan tingkat pengetahuan pelajar antara sebelum dan sesudah pemajangan poster dan leaflet di SMP 1 Patampanua Pinrang,

Hasil penelitian ini sejalan dengan penelitian yang dilakukan Fitriyah (2015) mengenai Pengaruh penyuluhan dengan media audio visual dan leaflet terhadap pengetahuan ibu tentng pemberian makanan pendamping ASI, menunjukkan bahwa penyuluhan menggunakan media audio visual lebih efektif meningkatkan pengetahuan MP ASI ibu. ${ }^{6}$

menurut WHO adalah dengan pemberian informasi untuk meningkatkan pengetahuan sehingga menimbulkan kesadaran dan pada akhirnya orang akan berperilaku sesuai dengan pengetahuannya tersebut. Salah satu upaya pemberian informasi yang dapat dilakukan adalah dengan pemajangan poster. ${ }^{7}$

Sikap seorang anak adalah komponen penting yang berpengaruh dalam memilih makanan jajanan. Sikap positif anak terhadap kesehatan kemungkinan tidak berdampak langsung pada perilaku anak menjadi postif, tetapi sikap yang negatif terhadap kesehatan hampir pasti berdampak pada perilakunya. ${ }^{8}$

Data pada Tabel 7. Menunjukkan bahwa dari 171 responden, 90,1\% responden yang memiliki sikap baik sebelum pemajangan poster dan leaflet meningkat setelah pemajangan poster dan leaflet sebanyak $98,2 \%$ Responden yang memiliki sikap kurang sebanyak 9,9\% sebelum pemajangan poster dan leaflet menurun menjadi $1,8 \%$ setelah pemajangan.

Berdasarkan analisis dengan menggunakan Paired sample T-test diperoleh nilai sign $=0,000$. Ini berarti bahwa ada perbedaan sikap antara sebelum dan setelah pemajangan poster dan leaflet di SMP 1 Patampanua Kabupaten Pinrang.

Romdiyatin dalam Maulana (2008) menyatakan ketidaktahuan tentang bahan makanan dapat menyebabkan pemilihan makanan yang salah dan rendahnya pengetahuan gizi akan menyebabkan sikap masa bodoh terhadap makanan tertentu. ${ }^{9}$

Salah satu faktor yang mempengaruhi pembentukan sikap adalah pengaruh orang lain 
yang dianggap penting. ${ }^{10}$ Dengan adanya informasi dari pemajangan Poster dan Leaflet tentang makanan sehat akan mempengaruhi tingkat pengetahuan dan sikap pelajar.

Hasil penelitian ini sejalan dengan penelitian Herlina (2017) tentang Pemanfaatan media poster dan leaflet makanan sehat dalam perilaku konsumsi makanan jajanan murid SD di Kecamatan Mattiro Sompe Kabupaten Pinrang menunjukkan ada pengaruh media poster dan leaflet makanan sehat terhadap tingkat pengetahuan dan sikap dalam perilaku konsumsi makanan jajanan murid. ${ }^{11}$

\section{KESIMPULAN DAN SARAN}

Berdasarkan hasil diatas, maka dapat disimpulkan bahwa ada pengaruh media poster dan leaflet terhadap tingkat pengetahuan dan sikap konsumsi makanan jajanan anak sekolah di SMP 1 Patampanua Pinrang. Dengan

\section{DAFTAR PUSTAKA}

1. Undang-undang No.36 tahun 2009. Ketersediaan serta keamanan pangan. 2009

2. Haloho; V.P. 2014. Keamanan Pangan Jajanan Anak Sekolah. Kabudsit Produksi kosmetik dan Makanan. Bogor

3. Badan POM 2011. Laporan Tahunan 2011. Direktorat Surveilan dan Penyuluhan Keamanan Pangan. Deputi Bidang Pengawasan keamanan Pangan dan Bahan Berbahaya. Makassar. kesimpulan diatas maka di sarankan Kepada pihak sekolah diharapkan untuk tetap melanjutkan menggunakan poster dan leaflet untuk memberikan informasi masalah kesehatan khususnya makanan jajanan dan masalah kesehatan lainnya kepada siswa atau bekerja sama dengan Program Usaha Kesehatan Sekolah (UKS) sehingga informasi yang disampaikan lebih efektif. Dan memberikan penyuluhan kesehatan di sekolah khususnya tentang makanan jajanan kepada pelajar sehingga pelajar dapat membedakan makanan yang sehat dan tidak. Dan kepada kantin sekolah diharapkan makanan yang dijual diberikan penutup makanan atau lemari kaca sebagai tempat penyimpanan makanan agar makanan tersebut tidak dihinggapi lalat yang menyebabkan penyakit, sehingga makanan yang dijual juga dapat dijamin kebersihannya.

4. Notoatmodjo, S. 2012. Promosi Kesehatan dan Perilaku Kesehatan, Jakarta: Rineka Cipta.

5. Solihin. 2005. Pemilihan Makanan Jajanan. Eprints.ums.ac.id. (Di Akses Pada Tanggal 04 Agusutus 2018)

6. Fitriyah. 2015. Pengaruh penyuluhan dengan media audio visual dan leaflet terhadap pengetahuan ibu tentng pemberian makanan pendamping ASI. Repository.ipb.ac.id. (Di akses pada tanggal 04 Agustus 2018)

7. Notoatmodjo, S. 2003. Promosi Kesehatan dan Perilaku Kesehatan, Jakarta: Rineka Cipta.

8. Notoatmodjo, S. 2007. Promosi Kesehatan dan Perilaku Kesehatan, Jakarta: Rineka Cipta. 
9. Maulana. 2008. Hubungan antara pengetahuan dan sikap dengan perilaku konsumsi jajanan di MI Sulaimaniyah Jombang. Journal.um-surabaya.ac.id. (diakses pada tanggal 04 Agustus 2018).

10. Anwar. 2000. Hubungan Status Gizi Anak dengan Perkembangan Motorik Kasar Anak Usia 1-3 Tahun di desa Glawahgaru Kecamatan Undaan Kabupaten Kudis Tahun 2007.
Download.portaigaruda.org. (Diakses pada tanggal 23 April 2018)

11. Herlina dan Karman.. 2017. Pemanfaatan Media Poster dan Leaflet Makanan Sehat dalam Perilaku konsumsi Makanan Jajanan Murid SD Di Kecamatan Mattiro Sompe Kabupaten Pinrang. Fakultas Ilmu Kesehatan Universitas Muhammadiyah Parepare 


\section{Lampiran}

Tabel 1. Karakteristik responden berdasarkan Jenis kelamin, Umur, Kelas pelajar di SMP 1 Patampanua Pinrang tahun 2018.

\begin{tabular}{ccc}
\hline Karakteristik Responden & Frekuensi & Persen $(\%)$ \\
\hline Jenis Kelamin & & \\
Laki-laki & 70 & 40,9 \\
Perempuan & 101 & 59,1 \\
\hline Umur & & \\
11-13 Tahun & 151 & 88,3 \\
14-16 Tahun & 20 & 11,7 \\
\hline Kelas & & \\
VII 1 & 34 & 19,9 \\
VII 2 & 29 & 17,0 \\
VII 3 & 25 & 14,6 \\
VII 4 & 26 & 15,2 \\
VII 5 & 28 & 16,4 \\
VII 6 & 29 & 17,0 \\
\hline Total & 171 & $100 \%$ \\
\hline
\end{tabular}

sumber data primer, 2018

Tabel 2. Distribusi tingkat pengetahuan sebelum pemajangan poster dan leaflet di SMP 1 Patampanua Pinrang tahun 2018

\begin{tabular}{ccc}
\hline Tingkat Pengetahuan & Frekuensi & Persen $(\%)$ \\
\hline Tinggi & 144 & 84,2 \\
Sedang & 27 & 15,8 \\
Rendah & 0 & 0,00 \\
\hline Total & 171 & $100 \%$
\end{tabular}

Sumber data primer, 2018

Tabel 3. Distribusi tingkat pengetahuan responden setelah pemajangan poster dan leaflet di SMP 1 Patampanua Pinrang tahun 2018

\begin{tabular}{ccc}
\hline Tingkat Pengetahuan & Frekuensi & Persen $(\%)$ \\
\hline Tinggi & 155 & 90,6 \\
Sedang & 16 & 9,3 \\
Rendah & 0 & 0,00 \\
\hline Total & 171 & $100 \%$ \\
\hline
\end{tabular}

Sumber data primer, 2018 
Tabel 4. Distribusi sikap responden sebelum pemajangan poster dan leaflet diSMP 1 Patampanua Kabupaten Pinrang tahun 2018

\begin{tabular}{ccc}
\hline Sikap & Frekuensi & Persen (\%) \\
\hline Baik & 154 & 90,1 \\
Kurang & 17 & 9,9 \\
\hline Total & 171 & $100 \%$ \\
\hline
\end{tabular}

Sumber data primer, 2018

Tabel 5. Distribusi sikap responden setelah pemajangan poster dan leaflet di SMP 1 Patampanua Pinrang tahun 2018

\begin{tabular}{ccc}
\hline Sikap & Frekuensi & Persen (\%) \\
\hline Baik & 168 & 98,2 \\
Kurang & 3 & 1,8 \\
\hline Total & 171 & $100 \%$ \\
\hline
\end{tabular}

Sumber data primer, 2018

Tabel 6.Pengaruh media poster dan leaflet terhadap tingkat pengetahuan konsumsi makanan jajanan di SMP 1 Patampanua Pinrang tahun 2018

\begin{tabular}{cccccc}
\hline \multirow{2}{*}{$\begin{array}{c}\text { Tingkat } \\
\text { pengetahuan }\end{array}$} & \multicolumn{2}{c}{$\begin{array}{c}\text { Sebelum } \\
\text { (pretest) }\end{array}$} & \multicolumn{2}{c}{$\begin{array}{c}\text { Sesudah } \\
\text { (postets) }\end{array}$} & \multirow{2}{*}{ Paired Sample T-test } \\
\cline { 2 - 5 } & $\mathrm{F}$ & $\%$ & $\mathrm{~F}$ & $\%$ & \\
\hline Tinggi & 144 & 84,2 & 155 & 90,6 & \multirow{2}{*}{0,000} \\
Sedang & 27 & 15,8 & 16 & 9,3 & \\
Rendah & 0 & 0,00 & 0 & 0,00 & \\
\hline Total & 171 & 100 & 171 & 100 & \\
\hline
\end{tabular}

Sumber data primer, 2018

Tabel 7. Pengaruh media poster dan leaflet terhadap konsumsi sikap anak di SMP 1 Patampanua Pinrang tahun 2018

\begin{tabular}{cccccc}
\hline \multicolumn{5}{c}{ Sikap } & \multicolumn{4}{c}{ Pemajangan poster dan leaflet } \\
& $\begin{array}{c}\text { Sebelum } \\
\text { (pretest) }\end{array}$ & \multicolumn{2}{c}{$\begin{array}{c}\text { Sesudah } \\
\text { (postest) }\end{array}$} & \multirow{2}{*}{ Paired Sample T-test } \\
\cline { 2 - 5 } & $\mathrm{F}$ & $\%$ & $\mathrm{~F}$ & $\%$ & \\
\hline Baik & 154 & 90,1 & 168 & 98,2 & \\
Kurang & 17 & 9,9 & 3 & 1,8 & 0,000 \\
\hline Total & 171 & 100 & 171 & 100 & \\
\hline
\end{tabular}

Sumber data primer, 2018 